Boise State University

ScholarWorks

$1-1-2015$

\title{
What New Writing Teachers Talk About When They Talk About Teaching
}

Heidi Estrem

Boise State University

E. Shelley Reid

George Mason University 


\title{
What New Writing Teachers Talk about When They Talk about Teaching
}

\author{
Heidi Estrem and E. Shelley Reid
}

As a discipline with academic roots in pedagogy (Harris 1996), composition studies has fostered increasingly visible and structured programs to mentor new writing instructors. Several recent essay collections compile examples of programs, thoughtfully theorized approaches, and careful explorations of how to best support and nurture new instructors of first-year writing (see, for example, Pytlik and Liggett 2002; Ward and Perry 2002). It is now common that new college writing teaching assistants (TAs) participate in at least one pedagogy seminar designed to guide them through their initial teaching experience and provide an introduction to composition studies (see Dobrin 2005). Additionally, individual accounts of new instructors like those by Wendy Bishop (1990), Elizabeth Rankin (1994), and Sally Barr Ebest (2005) help provide a rich context for further research on the pedagogical development of new writing instructors.

As two writing program administrators who have mentored new TAs and taught the pedagogy seminar for years now, we believed that our hours of work with these TAs - who are often simultaneously new to graduate study, new to teaching, and new to the concept of composition studies as a field - were affecting them positively. But how much, we wondered, did their encounters with new concepts about teaching and writing in our pedagogy course influence their approaches in the classroom? How did TAs make decisions about teaching, and why? To build on the important scholarship on TA mentoring, as well as to help us move from belief to knowledge about

Pedagogy: Critical Approaches to Teaching Literature, Language, Composition, and Culture Volume 12, Number 3 DoI 10.1215/15314200-1625253 $\quad$ (C) 2012 by Duke University Press 
how TAs make decisions and articulate their beliefs about teaching writing, Shelley designed a multiyear, multimodal research project; Heidi then added her program as a second site. The three-year research project included extensive surveys of TAs and anonymous interviews at both sites (the full project is described in much more detail in Reid and Estrem forthcoming). The rich perspectives expressed within the set of interviews - what new instructors talk about when they talk about teaching - kept drawing our attention again and again: these new writing instructors shared their perspectives on teaching, their hopes and fears, their insights and questions, and their frustrations in ways that helped us revisit and rethink what we thought we knew about how instructors experienced teaching for the first time.

What we gradually came to understand as we reread the transcribed words is this: while research within composition studies has focused quite a bit on teaching, there's not been quite as much focus on learning - in this case, learning about teaching. From the interview transcripts, we gain different glimmers of insights into how people learn pedagogy - how they conceptualize it, narrate it, make meaning from it, and integrate new ideas into their practices. One key message these TAs' voices provide us seems obvious now both in a "We already knew that!" way and in a "Why weren't we thinking more about that?!" way: learning to teach (writing) is a protean and lengthy process, its uncertain and recursive progress often obscured by the myths of quick competence on which learners, teachers, and institutions rely.

In this article, we focus most closely on two particularly compelling areas of the interviews that help reveal the complexities of learning to teach writing: first, at the macro level, the principles for teaching that the interview participants named and what they identified as the origins of those beliefs, and second, at a very particularized level, the stories of teaching challenges they chose to tell. Together, these accounts help us, in turn, come to know more about how new instructors learn pedagogy: not just how they learn about it or learn to practice it, but how they begin to learn to become the reflective practitioners we hope for. Part of what these TAs are telling us - Heidi and Shelley individually and all of us as a field - is that we are one of many sources of information and values about teaching (writing) that aid new learners. And part of what they tell us, less directly, is that we need to more overtly acknowledge and teach toward a slower, more recursive, and more extended learning process for new writing teachers.

In the analysis that follows, we first briefly explain how the interview methodology itself opened up new possibilities for imagining alternate spaces for our mentorship of new TA instructors. Then, and most impor- 
tant, we turn to the words of the TAs themselves, exploring what they say about teaching and what that might reveal about their learning processes. Finally, these data lead us to reconsidering current institutional structures and the implicit expectations embedded within those structures. Through taking seriously what these TAs talk about when they talk about teaching, we can productively rethink how we might provide mentoring that is focused, directed, and appropriate to the developmental stages that TAs are in as learners themselves.

\section{Methodology as Process and Result: Contexts for Dialogue in Writing Programs}

Although our interviews were initially structured as a data-gathering methodology, we have come to understand them as contributing to the thinking process, and especially the storytelling process, that the TAs participated in via our study. As Irving Seidman argues, "It is this process of selecting constitutive details of experience, reflecting on them, giving them order, and thereby making sense of them that makes telling stories a meaning-making experience" (2006: 1).

The methodological decisions made for this study helped illuminate TAs' stories in a different way than we had anticipated. While there are several excellent qualitative studies of TA development, and particularly of the graduate pedagogy seminar, we wanted to tease out possibilities beyond the local (for a fuller account of prior scholarship in this area, see Estrem and Reid 2012). Informed by our own instructional experiences, by the research of Rankin, Barr Ebest, and others, and especially by Mary M. Kennedy's Learning to Teach Writing: Does Teacher Education Make a Difference? (1998), we were confident we knew much of what the TAs we work with would tell us about teaching if we asked them directly. But we were curious about what they might say - particularly what they might say about their core beliefs and reasonings, not just their practices - if we weren't there.

So while we were mindful of Seidman's (2006: 7) concerns about all interviews conducted by those in positions of power - that it can be a "process that turns others into subjects so that their words can be appropriated for the benefit of the researcher" - Shelley ventured that a different approach to conducting the interviews might lessen (while of course not removing) the impact of our position as researchers of/with/among our own instructors/students. We wanted to at least try to mediate that complicated world differently for these graduate student instructors. TAs who volunteered for the interviews, then, were informed that we would be reading the transcripts. However, the 
interviews took place in a neutral setting (a department conference room or empty office) with an undergraduate or graduate research assistant, and were transcribed without identifying data. Twenty-nine interviews were conducted at George Mason University over a three-year period; twelve were conducted at Boise State University over a two-year period. (Some students were interviewed in more than one year, but we were generally unable to track these repeated participants.) The interviews were designed to gain insight into how these new TAs negotiated situations in the classroom and what principles they identified for their teaching (and where they came from), and then to assess whether they applied those principles (or not) to various aspects of teaching, from planning a syllabus to responding to student writing. (See Appendix A for descriptions of the two sites and Appendix B for the full survey.)

This method had some surprising benefits; first, however, it seems appropriate to acknowledge its limitations. While one goal of conducting a two-site, longitudinal study was to gather data that would let us trace the impact of local pedagogical structures and TAs' development over time, we have no solid reports to make here on those counts. Although we gathered data about each participant's site, status (first- through third-year), prior experiences, and other demographic information, we saw few reliable patterns of difference along any of these lines. Whether that is a consequence of too limited a sample, too similar sets of participants (neither site grants $\mathrm{PhDs}$ or has many rhetoric and composition concentrators), or too short a time for observation of TA development is not clear. It's also conceivable that there really are few major differences across these lines of investigation, a possibility that could potentially affect TA preparation significantly; with limited data, though, we offer such suggestions guardedly in this article. In addition, the research assistants conducting the interviews did not always know the program as well as we did and therefore missed opportunities to follow up. Finally, the interviews still were clearly going to be reviewed by the TAs' supervisors and took place in the department's building and with questions designed by us, leaving TA participants still very much embedded in their institutional situations.

The design of the study does deliberately privilege a degree of anonymity for the participants over a concern for understanding their learning through what would be a more recognizably "contextualized" approach — for example, through a teacher-research approach or through a qualitative study of new TAs. However, as we read and analyzed these transcripts, it was clear that they were not $d e$ contextualized: they were differently contextualized, to be sure, but they were also grounded in our individual program values, our 
university contexts, even in the relationship between the interviewer and the TA. The interviews themselves came to function as "social interaction[s]," providing a way for participants to "generate new reactions" (Briggs 1986: 22). The social interactions in these interviews led to dynamic, grounded responses in a space different from those often used for research on new instructor development.

These social interactions occur as a kind of temporary context in what we might label a "thirdspace" (see Edward Soja's voluminous scholarship). While cultural communication theory operates at a dramatically different level than our own study does, Soja's metaphor gives us a lens for considering these conversations. As he explains, "Thirdspace is a metaphor for the necessity to keep the consciousness of and the theorizing on spatiality radically open.... It is a purposefully tentative and flexible term that attempts to capture what is actually a constantly shifting and changing milieu of ideas, events, appearances, and meanings" (1996: 50). But we found the interviews' thirdspaces (neither seminar nor office chat, neither department mailroom nor online discussion) allowed the TAs' stories of teaching identities to shift and deepen in meaning even as they were talking. The transcripts help us assess ways that we, as their mentors, might create other kinds of spaces for this development work. We aren't claiming that these interviews represent a deeper or more "honest" truth than, say, our own classroom-based research with these same TAs, or the largely qualitative, case-study-based research that's been done with this population of developing TAs up to this point. Instead, though, we do propose that these TAs' stories - as told through these interviews with a disinterested third party - convinced us that alternate spaces could change how teachers spoke, what they spoke about, and what knowledge was created through their talk about teaching, an idea we return to at several points in this article.

\section{What TAs Talk about, Part 1: Principles and Where They Come From}

Educational researchers remind us that new teachers are not new to the classroom, but just to the front of it. Jo Sprague and Jody D. Nyquist (1989: 44-45) identify beginning graduate students as "senior learners," on their way to becoming "colleagues in training" and then "junior colleagues." As a whole, the interviews elicit how these senior-learners-becoming-colleaguesin-training make decisions about preparing for class, writing a syllabus, and facing challenges in the classroom. In reading the transcripts, we have found that, indeed, "If given a chance to talk freely, people appear to know a lot about what's going on" (Bertraux, quoted in Seidman 2006: 39). 
Table 1. TA principles about teaching

\begin{tabular}{lcc} 
Principles about teaching related to ... & Number of times mentioned & Frequency \\
\hline $\begin{array}{l}\text { Pedagogy of approach: } \\
\quad \text { Classroom practices (29) }\end{array}$ & 45 & 37 percent \\
$\quad$ Engagement and community (16) & 46 & 37 percent \\
Pedagogy of content: & & \\
$\quad$ Teaching writing as a process (22) & & \\
$\quad$ Expanding students' understanding of writing (18) & 16 & 13 percent \\
$\quad$ Teaching critical reading (6) & 14 & 11 percent \\
Focus on encouraging students & 2 & 2 percent \\
Focus on student learning & & \\
Other &
\end{tabular}

Embedded in the middle of the interview protocol are the two questions that produced the data we will first describe and then analyze in this section:

1. What do you see as three to four key principles for your teaching or tutoring of writing?

2. Could you say where those principles come from or are related to?

\section{Categorizing TAs' Principles}

Within the set of forty-one interviews, we identified and categorized more than one hundred identified principles or beliefs (123, to be exact). As we sifted and recategorized, these named principles gradually coalesced into four main areas (see table 1). TAs shared principles related to

- $\quad$ pedagogies of approach (what TAs might $d o$ in a particular class meeting);

- $\quad$ pedagogies of content (what to teach students about writing [and reading]);

- $\quad$ encouraging students; and

- student learning.

As so often happens, two TAs identified principles that we could not categorize neatly, and these make up the "other" category.

These principles are wide-ranging; they reveal TAs' beliefs about student learning, instructor behavior, what "good" classrooms look like, and what the day-to-day teaching of writing should be. Across both programs, TAs emphasize the importance of garnering student "engagement" and building a sense of classroom community; they value teaching writing as a complicated, messy, social process; they are committed to encouraging students 
and have begun to think about students as learners. And as they talk in this thirdspace, they articulate their principles in an amalgam of generalized and field-specific tropes, revealing even as they gain knowledge and experience that they remain in transition between "senior learner" and "colleague in training."

\section{Pedagogy of Approach}

The responses coded as principles related to a pedagogy of approach document how TAs envision classroom practices and approaches to teaching. The twenty-nine labeled "classroom practices" comprise the most varied response category - and the most frequent. They include principles about general approaches ("whatever it takes to get the job done"), instructor preparation for a class session ("preparation about the subject at hand"), working with students ("ask questions," "listen before you talk"), and recommended classroom approaches ("it's okay to joke," "find a concrete metaphor to explain an idea"). Also captured within this category is a set of responses about the importance of creating a class that functions like a community and that emphasizes "engagement." These areas were mentioned frequently and consistently enough to warrant their own subcategory as an important aspect of approaches to teaching. The following are examples of the kinds of responses within this category:

I would say one [principle] is student engagement, really finding ways to engage students not just in the classroom time, but also in the projects.

[One principle is] developing a community feel in the classroom, so that they can go to other students and work with other students, and it's not just learning from me, who is kind of their peer. ... And I think it's good to develop more of a community of writers rather than just like student/teacher.

\section{Pedagogy of Content}

The next cluster of TAs' principles focuses on the content of the course. In these, TAs describe a commitment to teaching writing as a process, to expanding students' current understandings of writing, and to engaging them as critical readers. When articulating beliefs about writing process, they named twenty-two principles. For example:

So, it's really important to make sure that students realize that writing is something that is important and valuable, but is mutable at the same time. That it's changeable. It's not set into stone. 
For me it was really teaching them that something comes before the draft so I really wanted to instill in them that whether you do an outline or a brainstorm map or just take notes you need to do something before you sit down at that computer screen 'cause you'll freeze.

These TAs identify also a number of principles (eighteen) related to challenging first-year students' initial conceptions of writing. They see their role as advocates for an enriched, expanded notion of what writing is and what it can do:

Well, firstly, I want them to know that writing can be fun. It's not necessarily as one-answered single - there's no one answer. There's room when writing to play. Even when you're writing an academic research paper, there's room to make your own way.

I really want to try to expose them even briefly to a real range, not just of writing styles or genres but also situations, presentations, conferences.

Additionally, a small but significant cluster of responses (six) addressed the importance of teaching critical reading.

\section{Encouraging Students}

In both programs, TAs hold strong beliefs about the importance of encouragement: that writers learn by knowing what they're doing right, that encouragement leads to better learning, and that it should be a part of teaching. Sixteen beliefs were similar to the following examples:

I think the second principle is to try and encourage students to be open to positive, constructive criticism.

Number one is generosity; to care about the students' lives and not just their academic work.

I try to think like a student who would struggle with the subject ... I try to think, if I was a student who wasn't interested in writing, didn't feel I was good at it, all of these sorts of things, what would help me and what would help me at least appreciate it more or do better or at least see that I could get through it, even if it wasn't ever gonna light my pants on fire.

\section{Student Learning}

The final category includes principles about how people learn and about cognitive development. Here, TAs name fourteen beliefs about the conditions 
for learning ("people learn by doing," "people don't learn by just hearing it once"); about what first-year students need to learn ("individual accountability in group work," "making them follow the prompt"); and how first-year learning fits in with the fuller college experience ("meta-knowledge," "connections to other classes").

\section{Analyzing TAs' Principles}

Collectively, these named principles or beliefs about teaching have much to encourage those of us who work with new teachers. Within a short time frame - only a few years at most - many of these TAs have formed thoughtful, engaged principles (and some quirky ones as well). Even though we only read the transcripts, the earnest tones of their spoken voices come ringing through: these TAs care about teaching and teach based on deeply held principles. At the same time, TAs use a lot of generalized language here - even when prompted by the more "academic" word principles. TAs who, in the pedagogy seminar, routinely use phrases like collaborative learning and recursive process are talking in less specific language ("community feel" and "something comes before the draft"), causing us to wonder how much they are envisioning the rich traditions and scholarship of composition pedagogy and how much they are drawing on their own preferences as students and writers.

Moreover, some TAs' answers are so brief or underdeveloped that we are more keenly concerned. As one example, we can imagine some of the strategies that this TA might resort to in her earnestness to "get the job done":

I don't really know if that's a principle, but I guess it's just sort of whatever it takes to get the job done.... You know, they definitely - I - I want them to have every chance to succeed, and to succeed means to meet those outcomes. So, like, if that means that I have to do things that I don't feel . . . is a proper (air quotes) use of time, then that's what I'll do. Right? 'Cause ultimately, I want them to be - when they leave this class to meet those outcomes, to have a decent grade, to be able to do what they're supposed to do in other classes.

The layers of responsibility this TA is beginning to articulate - to her students, to program-wide goals, to classes after first-year writing, to students' performance in the class - point to both an ethic of care and commitment as well as a kind of near-desperation that worries us, particularly when we peel back the next layer and look at where these principles come from. For this TA, this was nearly her full answer. She didn't identify where these beliefs 
come from, and if this is the extent of her beliefs about teaching, they seem, well, pretty thin.

Viewing the responses as a set also confirms for us the value in looking cross-institutionally. While there are, of course, site-specific references (to particular readings here and there; to tutoring, which was an experience all TAs had at George Mason University, and so was of course much more common in their replies), for the most part, the named beliefs were not readily identifiable by us - as their immediate mentors - as site specific. As we discuss in further detail in the next section, this similarity in their beliefs likely stems from the combination of beliefs they hold prior to teaching as well as the impact of composition teaching principles.

\section{Identifying Where Beliefs Come From}

We were particularly interested in understanding more about how TAs identified the origins of their beliefs through answering the follow-up question, "Could you say where those beliefs come from?" After all, nearly one-third of these interviewees were taking their pedagogy seminar during the semester that they participated in the survey. Within this set of questions - about naming their beliefs and the origins of those - it made sense that we might see the most impact of our work with TAs. We hoped to gain a stronger sense of how TAs integrated new and previous knowledge about teaching and learning writing.

For each named principle, we then listed and analyzed what the TAs identified as the origins for that particular principle. The TAs identified their principles or beliefs about teaching writing as being derived from

- formal study, including composition scholarship;

- personal experience, belief, family value, or intuition;

- $\quad$ experience teaching or tutoring; and

- the community of peers and mentors within which they work.

However, there is often not a one-to-one correspondence; many TAs identified multiple sources as the origin for any particular belief. For example, TA responses to the question "Could you say where those principles come from or are related to?" frequently looked like this:

But I've done a lot of reading, obviously, about pedagogy and teaching and students. Then I've also been in the classroom and talked to students. So I think it's probably a mixture of all those things, not that I could specifically point to one instance or anything like that. 


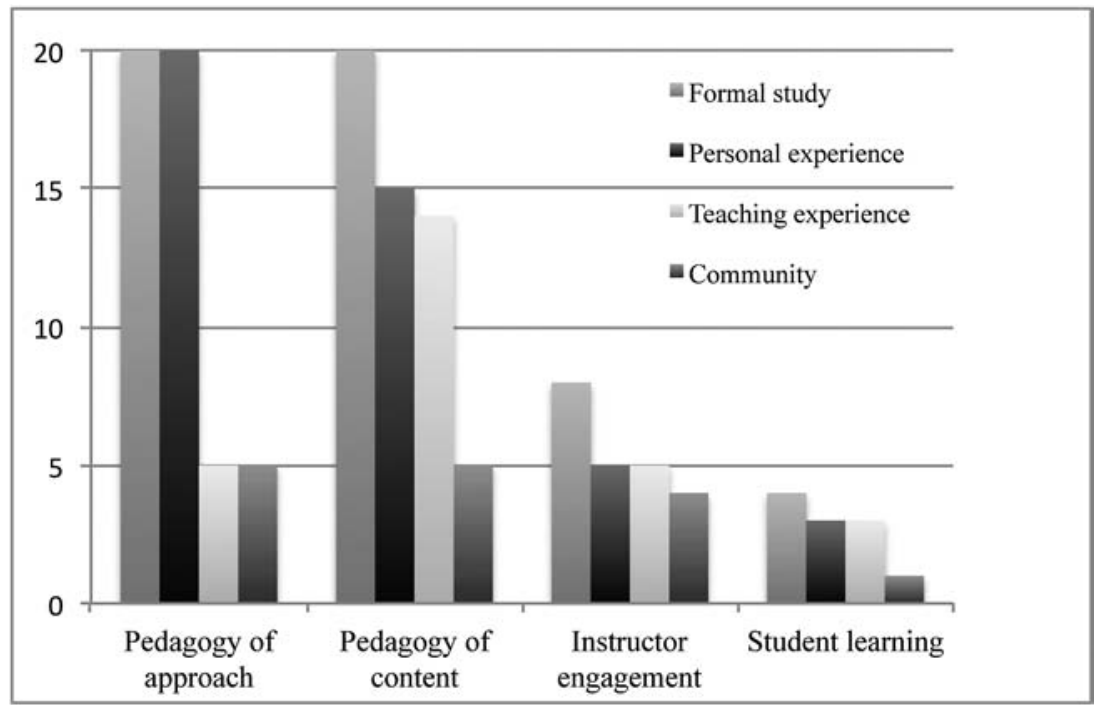

Figure 1. Origins of principles and beliefs

I just think they come from my experience as both a creative writer and my experience in the two pedagogy courses that I've taken.

We separated each identified "origin statement" within each category (pedagogy of approach, pedagogy of content, engagement, and student learning) and then coded the identified "origin" for each statement as explained above. When all responses are analyzed, several patterns emerge.

For example, within the twenty-nine initial principles or beliefs identified as related to "pedagogy of approach," formal study and personal experience were both named twenty times, while teaching experience or the influence of peers/community were each mentioned five times. (A caveat: these charts are not intended to support any fine-grained quantitative analysis, but they are helpful in making general trends visible.) When asked to identify where their beliefs come from in all of these areas, for instance, TAs note the influence of formal study most frequently for all areas. Formal study principles are what we might expect (and hope) to see informing their beliefs: those new to teaching (and often new to the field of composition studies) are locating their principles for teaching in what they have learned through participating in pedagogy seminar(s), receiving training for Writing Center or teaching, or through reading articles. (In TAs' language, formal study was represented in a range of ways: "the pedagogy course," "Freire," or "that underlife idea [Robert Brooke].") 
In the second set of teaching principles rooted in personal experiences or beliefs, sometimes TAs noted their own experiences as a student or writer; other times they noted the influence of family or personal values. For example, TAs noted that their principles came from "what I liked as a student," "[the fact that] my mom's a teacher and she approached it in that way," "[what] works for me as a writer." As fig. 1 shows, in each of the four categories of TAs' principles, personal experiences figure quite strongly. A third set, focusing on principles drawn from TAs' own prior classroom teaching (or tutoring) experience, figures most strongly in the category of "pedagogy of content." This makes sense: brand-new TAs likely know very little about the content of the courses, and so formal study and their own personal experiences still figure strongly in this area - and yet like the rest of us, TAs eventually base what they teach on prior teaching experiences. How they approach teaching first-year writing is influenced slightly less by prior teaching experiences. Finally, while in other areas of the interviews (beyond the scope of this article) our coding for community of other instructors is quite frequent, within their discussions of principles, fewer TAs name the influence of mentor TAs or peers. (In this category are responses like "watching my mentor TA teach" and "peer mentor.") They draw from their community of peers and mentors quite a bit when imagining a course, dealing with challenges in the classroom, or creating assignments (issues covered in other areas of the interviews) but do not link their beliefs or principles about teaching writing to their peers very often.

Overall, we find these patterns both encouraging and cautionary. Our work with new writing teachers in the pedagogy seminar and in one-on-one mentoring can directly affect their approaches to the classroom in ways they recognize and can name: they talk of concepts like encouraging engagement and inquiry or emphasizing peer review. Since many TAs never took firstyear writing themselves, one potential high-impact area for us as mentors is in helping them rethink what the writing class looks like and feels like. It's also clear that their own experiences teaching or tutoring influence what they teach more heavily, and there is steady influence from a wide range of personal beliefs that we - and maybe they - may not know about unless we ask them directly. Moreover, when combined, these extracurricular sources (peers, teaching experience, and personal experience) outweigh our instructional voices in TAs' responses; again, this is not a new concept for educators to face, but we realize we have not always been so mindful of it in our pedagogy courses, where we are predisposed to see our effects on our students, and they are predisposed to remind us of our influence. And lastly, it seems 


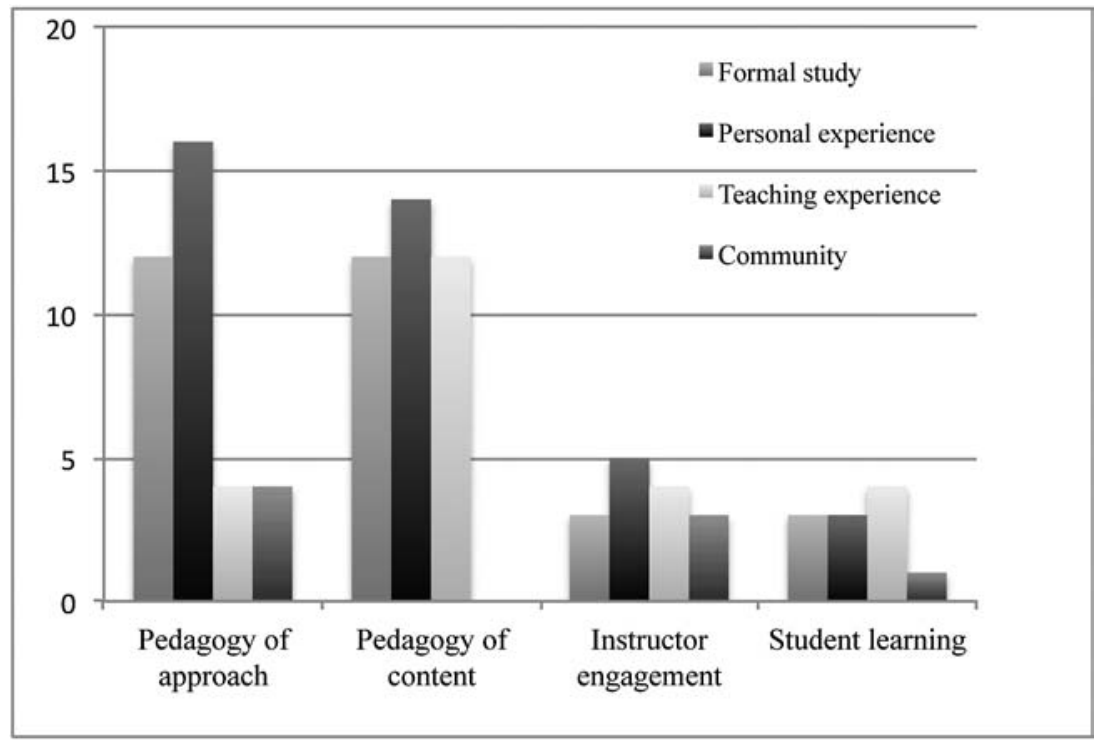

Figure 2. Origins of principles and beliefs: First mention only

that while TAs do turn to peer mentors for practical help, they have less frequent theorized or reflective conversations with peers - a pattern which reinforces our interest in creating new spaces where all TAs can engage in such conversations.

Caught between pleasant surprise and mild doubts about seeing "formal study" informing TAs' core beliefs at higher levels than other sources, we also wondered how the data would look when only the initial responses given were coded. We had noticed that many respondents began by naming teaching experiences, or a personal experience, and then added phrases like "the readings too, but I can't say which one." So, when we look only at the first response given, the numbers distribute somewhat differently.

As a parallel example of the numerical groupings behind this chart, for all initial principles or beliefs coded as "pedagogy of approach," the number of initial identifications of the origins of that particular belief is now as follows: formal study, twelve; personal experience, sixteen; teaching experience and community, four each. This graph (see figure 2) makes visible how and when personal experience and classroom-based experience were most readily recalled as the source of each principle. In the category of "pedagogy of approach," personal experience comes quickly to mind for the TAs: though they also acknowledge sources like "the pedagogy course" or "readings I've done," they are more likely first to identify their principles as based 
in what they've experienced in the classroom as students, what they know and believe about human behavior, and what they value. (Their teaching/tutoring experiences are less influential within this area.) In other words, TAs draw on some principles about how to teach writing that they see as rooted in personal experience - values that are in place before an instructor sets foot in a classroom with which they have either no or very little personal experience.

In the area of "pedagogy of content," teaching experience and formal study are slightly secondary to personal experience, although all three areas are identified frequently by these TAs. In the area of principles related to the importance of encouraging students, the first named origin is most often personal experience, followed by teaching experience and formal study. In the area of student learning, teaching experiences become most important: new teachers' observations of their own students prevail over data and theories about writing and learning. Of course, the differences between these numbers are quite small. What interests us more are the trends we see here in where, how, and why these TAs name the origins of their beliefs.

Again, it's complicated. We're glad, in fact, to see new instructors of writing voluntarily identifying multiple sources that inform their teaching beliefs. These patterns are useful in two ways. As the mentors of these instructors, we can see more about the beliefs new TAs are developing or already have in place so we can build from those resources to expand their repertoires. Additionally, these responses remind us that if we choose to ignore the many areas of their lives and experiences that new (and continuing) instructors draw from as we teach, we're missing a large portion of the picture. Our TAs' talk reminds us that new learning does not replace earlier learning as much as it synthesizes with earlier understandings, sometimes wholly and sometimes partially, attaching readily when new and old principles match, and perhaps less strongly when there are conflicting principles. Some "resistance" might thus be productively reframed as a normal stage of TAs' learning processes, or lessened through inquiry about the origins of long-held values.

These conversations about principles reveal thoughtful, resourceful instructors who take teaching seriously and approach it with a wide range of perspectives - and whose voices sometimes surprise us with their certainty about their principles. Their beliefs help us understand more about what they think about teaching and where they locate their beliefs; as a next step, we can consider how we might encourage these TAs to continue revisiting and deepening these principles. Reading their words as they work with the interviewer to understand the question and to consider and name how and 
why they teach underscores for us the importance of ongoing reflection and reconsideration, of creating multiple spaces for reflection. It may matter to scholars and teachers in the field, for instance, that TAs encourage revision because scholarship demonstrates its value as a learning mode for writers rather than only because they just believe it's important. Moreover, their growth as reflective practitioners - as well as their ability to defend, change, or pass along their practices - may depend on how they perceive and articulate their reasons for taking pedagogical action.

We are mindful, as well, of an apparent lack of differences among responses from first-year TAs as opposed to second- and third-year TAs: our results strongly suggest that all of our TAs would benefit from more opportunities to name principles, connect them to multiple sources, and reflect on them. Without such prompting, new instructors might settle on a set of absolute principles quite early (e.g., "I always privilege classroom community"); the good news is that the transcripts also demonstrate how easily a space for guided teacher-talk can provide other opportunities for articulation and reflection. As mentors of these new instructors, we are reminded of how crucial it is to provide varying kinds of support for the kind of interactive intellectual work that new instructors need to do, and to time our support to match learners' developmental stages. For example, many pedagogy education programs ask new TAs to write a teaching philosophy as part of their course work in their first or second semester of teaching. However, our interview transcripts point to a different timeline: a structure for working with new TAs that might encourage them to name and revise principles for teaching throughout their experience in a program, drafting and redrafting these ideas in workshops, in colloquia, in online spaces, and through guided discussions that extend and amplify the pedagogy education process.

\section{What TAs Talk about, Part 2:}

\section{Tricky, Difficult, or Surprising Teaching Situations}

While asking TAs to name beliefs necessarily leads to larger, philosophical perspectives, asking them to share specific accounts of teaching (and then to reflect on them) illuminates how new instructors identify and describe the particular. In this section, we focus on the responses to the following set of questions:

1. Please tell me a little about a tricky, difficult, or surprising situation you encountered recently in a writing class or while tutoring regarding a writing student. 

2. How did you respond?
3. Why did you respond in that way?

Here, then, we take up what TAs talk about when they share anecdotes of teaching not directly related to their principles or beliefs for teaching. The ways in which TAs describe challenging situations they have faced stand out in the interview transcripts as some of their longest responses (see table 2). The forty respondents to this set of questions (one TA couldn't think of a situation) provided responses that we have coded globally as stories of pedagogy (understanding these teaching-related situations as teaching moments for themselves or as pedagogical issues) and stories of students (of resistance, of students learning how to be students, of appropriate student-instructor relationships). To approach these rich narratives in a systematic way, we first identified the two overarching patterns we saw in these accounts and then worked to code the narratives according to these main themes within the stories of pedagogy and stories of students.

Three accounts from the stories noted in table 2 have also been identified as "unsanctioned" accounts: detailed experiences identifying challenges or solutions that we - and often the TA - recognize as "out of bounds" of program norms and recommendations. We say more about those below.

\section{Stories of Pedagogy: Reflective Practice}

Fourteen participants use the prompt to describe and reflect on stories of pedagogy: stories about adjusting their teaching approaches, about lessons that went well and lessons that didn't. We have included longer excerpts from the transcripts here in part because they reveal how TAs are using the interview as a processing space, building an answer phrase by (sometimes hesitant) phrase. The narratives also demonstrate how single events - the kind that may occur in one's first, fourth, or even twentieth semester of teachingprovide opportunities for and sometimes even demand continuing learning about teaching.

Among the stories of pedagogy, three accounts demonstrate a particular stance that we've identified as "reflective practice" — that is, the TAs use the moment of the interview to discuss how they have rethought their own approach or their role in the classroom. For example, a third-year TA describes how she learns from students through thinking deeply about her own beliefs and approaches as well: 
Table 2: Types of difficult teaching situations

\begin{tabular}{|c|c|c|}
\hline Theme & $\begin{array}{c}\text { Number of } \\
\text { interviews (total } n=40)\end{array}$ & Characteristics \\
\hline $\begin{array}{l}\text { Pedagogy: } \\
\text { Reflective practitioner }\end{array}$ & 3 & $\begin{array}{l}\text { These accounts identify the challenge as } \\
\text { located (at least partially) in the } \\
\text { instructor's choices, and demonstrate } \\
\text { the willingness of instructors to learn } \\
\text { from their students and adjust their } \\
\text { approach. }\end{array}$ \\
\hline $\begin{array}{l}\text { Pedagogy: } \\
\text { Classroom or program }\end{array}$ & 11 & $\begin{array}{l}\text { These accounts position teaching events } \\
\text { (organization, working with readings, } \\
\text { adjusting after a substitute) as the key } \\
\text { challenge. }\end{array}$ \\
\hline Students: Resistance & 14 & $\begin{array}{l}\text { These accounts identify the challenge as } \\
\text { stemming specifically from what } \\
\text { participants identify as student } \\
\text { resistance. }\end{array}$ \\
\hline Students: Studenting & 7 & $\begin{array}{l}\text { These accounts note student behavior as } \\
\text { a challenge - behavior that's not } \\
\text { necessarily resistant but is about } \\
\text { individual students learning to handle } \\
\text { school, such as a student who misses a } \\
\text { lot of class or who needs personal help } \\
\text { beyond the classroom. }\end{array}$ \\
\hline Students: Relationships & 5 & $\begin{array}{l}\text { These accounts focus on the challenge } \\
\text { of how to address the more general } \\
\text { interpersonal arenas of teaching. They're } \\
\text { stories of authority, age, and } \\
\text { "appropriate" behavior. }\end{array}$ \\
\hline
\end{tabular}

I have a student who is Catholic and her papers tend to be - she tends to argue from a belief stance, and thesis statements of belief are very difficult in terms of how to lay out an argument, and I don't want to discourage her from exercising her faith and her passion, and so just trying to balance a respect for her faith and also help her to recognize some fallacies that can come into play with, you know, the world being the enemy and, you know, those kinds of things; so trying to help her explore the complexities of an argument that may be based on her belief system, but that she might not be able to argue from the Catholic standpoint, and have it be effective towards convincing someone who doesn't believe, who isn't Catholic.

So, but she seems to be, you know, responsive to that. It's tricky for me, you know, in terms of - and I, you know, I'm a Christian, so I want to make sure that I'm not biased too, so those are kinds of - that's probably one of the more unique 
tricky situations that I deal with is religion in the courses. You know, you have to be very careful about how I don't present a bias. ... I have the students talk [laughs], you know, and if this is your religion, you know, I'd love to have you share it with the class and how it relates to this issue, and ... I'll say "Okay, if you put this in a paper, what are some concerns that I would have about what you just said?" and they usually can tell me ... I'm not as familiar with some of the diverse religions in this campus and I learn from them, and I think it's really important to not come across as the teacher is the know it all and they're the trash receptacles that I dump things in, and I think they bring a lot to the table in terms of discussion that I wouldn't have thought of so - and they respond very well to each other and very passionately, and if I don't get in the way of that sometimes they can create their own lesson, and to me that's a dynamic thing to watch.

While this narrative begins as a reflection on the challenge of working with one particular student, the TA quickly moves beyond this example so that it does not remain a story of student resistance. Instead, she reflects on her own awareness of her likely biases, and she reminds herself what she has to learn from her students. We were glad to see these kinds of accounts - where TAs turned voluntarily to deep reflection - but there were only three such stories. As mentors of these TAs, then, we are mindful of needing to create more opportunities for all TAs to solve (or at least untangle) their teaching "challenges" through reconsidering them, through exploring multiple angles and approaches, and through drawing on resources that they have readily available to them.

\section{Stories of Pedagogy: Classroom or Program}

In other narratives related to teaching issues, eleven participants describe the challenges of teaching particular aspects of writing and how and why they made adjustments, though they do not explicitly articulate how they reflected on and learned from the experience. Indeed, many of them seem to be fully articulating the story, seeing all its pedagogical implications, for the first time, even reliving it as they create it. In the following account, a third-year instructor explains the challenge she faced when she hadn't integrated readings into her course very well:

You know it was just that, I mean I guess everyone hates their text, the first one they do. My readings were grouped by like topic. And so one of the topics worked great and I did a little like literature review. The other topics were sort of and gentle, and as I saw like kind of the decrease in quality in the reading responses and class discussion never really took off, I decided to kind of just make sort of a organic 
class decision that we would just start focusing on the writing, so we were getting into the bigger writing projects. I mean something that made sense to me, but at the same time I was like don't even buy this reader. It just never really panned out.

I think because there are so many in 101, that to me the main one was always the writing. I knew that they would have to focus on close reading in 201, so it was kind of like if you can't do everything, which of course I tried to do. You know I think I just decided that 101 goals put more emphasis on focusing on the writing projects versus the barely applicable readings.

While this "organic class decision" is not necessarily one we'd make or encourage as a mentor, her rationale for how she addressed this challenge is intriguing, reasoned, and based on her newly acquired professional knowledge: she knew that the next course in the sequence, an introduction to literature, would focus on close reading, and so she felt comfortable making this kind of one-time adjustment.

Several other transcripts also demonstrate that TAs often make decisions about how to address challenging situations by drawing on their knowledge about the program, course goals, or university culture. For example, another second-year student shares an experience in his second-semester class: drafts came in that didn't follow the guidelines for that assignment at all. He "knew," he said, that "101 knowledge wouldn't necessarily transfer" into his course - so he knew that he needed to teach and give time for revision. Because he had planned for it, he was able to respond by holding a "revision boot camp" in class, and as he'd predicted, the second drafts were much better. His already developing sense of how people learn through the arc of the program ensured that he faced this challenge with forethought rather than frustration.

A first-year instructor articulates a challenge that he also approached with a larger context in mind. He details the challenge of teaching students how to do exploratory writing rather than the argument-based writing they were more comfortable with, and he relays his struggle to really teach students how to explore in their writing. While he didn't have a lot of resources to draw from - his strategies for responding to this challenge were to "be there for the students when they struggle" - he shows awareness of the larger teaching goals at stake: he notes that "the goal is to teach. I want them to struggle, to experience cognitive dissonance." Accounts like these show instructors addressing pedagogical challenges through a sense of their larger goals for teaching and their role within a program. Their attention turns inward to their own decisions about what and how to teach in a writing class. 
However, these fourteen pedagogy-based accounts make up only about onethird of the narratives.

\section{Stories of Students}

The majority of TAs, when asked this question, did not choose to tell stories about a pedagogy challenge. Instead, the stories involved students in a variety of ways. Fully seventy-five percent of these narratives (30 out of 40 ) revolved around challenges with students: stories of resistance (16), student behavior (9), or student-teacher relationships (5). We're treading tentatively here, as we want to be true to the data - and we are also aware of how carefully these new instructors were working to unpack teaching challenges and think through why they occurred. These new instructors, then, weren't blaming students. There were moments of frustration, but the frustration was rooted in not feeling successful with a particular student - and usually not in it being the student's fault. That said, for the majority of respondents, a "teaching challenge" was a "student challenge."

\section{Students - Resistance}

In accounts we've coded as being about student resistance, these new instructors are stymied by teaching challenges that seem to be related directly to students' attitudes about the course and most use the word "resistance" in their account. For example, this first-year instructor explains his challenge:

I currently have a student who hates technology, to the point where he wants to type all of his stuff out on a typewriter. And that would be okay with me, except that we build Web sites for unit one. So, that was a real challenge . . . he didn't want to talk to me. He didn't want to seek my help. He didn't wanna, like, anything else. And I just sort of had to keep telling him to come talk to me, but he never did. So, he ended up turning in his stuff late. And so now the dilemma is, like, according to my late policy, he should get docked a certain amount of points. And do I dock him for his resistance to technology, or do I - you know, so, that's sort of a challenge.

And another first-year instructor relates a similar tale of resistance and frustration:

But I did have a tricky situation with my . . . class. When I first came to class, I had a student who was particularly challenging. Everything I said he questioned, and he was the worst enemy as far as peer support went. He wasn't very well liked in the class. Luckily, he didn't kind of turn the tide as far as the class was concerned. But I had to really work on my own judgment of him, because I didn't particularly care for his personality. But I had to listen to what he said, and I had to respond each time in 
a patient manner. Because letting yourself become impatient in front of the classes, I think, is not a good trait of a teacher. So he really tested my patience. Every day he had a challenge that he had for whatever it was I had said. And, you know, one time it was I told them that on their blog they couldn't use text messaging language. And he brought up some linguistics theory saying, like, "Doesn't language always change and aren't we the ones who create our own language?" which would've been, you know, interesting arguments and valid if he wasn't presenting them simply to annoy. I mean, he's just that kind of person. So on the one hand, I wanted to listen to his arguments and maybe discuss that. But I also didn't want him to take up too much of the class time with something that was disingenuous. Yep, he would also say things like - when I had them get into a circle, he said, like, "That's hippie shit. My parents taught me not to trust hippies," you know. So he was also very aggressive. But he disappeared about couple months into the class if that, maybe month and a half. $\mathrm{He}$ just disappeared. So he took care of himself.

Students who don't respond to instructors' good intentions, to repeated attempts to provide support, or to the course in general are described as "resistant" in a variety of ways. For new instructors, clearly individual student reactions loom large.

\section{Students - Studenting}

Other accounts stem from student behaviors, or what we call studenting: what to do with students who don't come to class, who come unprepared, or who are dealing with challenges in other parts of their lives. For example, this second-year TA tells a narrative that shares features with other stories in this category:

I had a student who e-mailed a couple of months ago and said that he was having some emotional issues and then he asked if I could work with him. He had only missed a couple of days of class at that point. I said, "Sure, I can work with you." But then I didn't hear from him for four weeks I think, so I had just kind of assumed at that point that he had dropped the class or that he wasn't planning on coming back to the class, because my attendance policy was pretty clear. But then he showed up in class and so this addressing this, having to talk to him about how I couldn't pass him in the class after he had missed that much class time. That was tricky.

A second-year TA explains the challenge of a certain kind of writing center consultation:

Well, I had something happen to me that happens not extremely frequently but sort of often where someone comes in, and it's not they don't want to be there, but they 
just sort of want to answer the questions themselves before really reflecting on it I think. And so at that point you do sort of have to try to ask more pointed questions and sort of try to slow things down I think; even directly saying, "Hey, let's just sort of - we don't have to rush; let's just kind of take things slower." Make sure you communicate it.

These accounts show how new TAs work to understand how learners behave, and why, and what their roles as instructors are. These situations require decisions about how - and how intensively - to intervene when a student is off track. Since even experienced teachers often make such decisions situationally rather than based on a consistent rule, these instances reveal a category of teaching challenges that involve reflective problem solving.

\section{Student-Teacher Relationships}

Five of the accounts reveal these new TAs' struggles with appropriate student-teacher relationships. Since new TAs inhabit the roles of graduate students and of instructors, it's not surprising that some challenges arise here. The following account, from a first-year TA who is describing an experience while working in the writing center, exemplifies the kind of challenges within this category:

My biggest problem as a tutor was a student who had actually violated the [restriction on the] number of sessions.... And he was a really nice guy, but he wanted me to do everything for him, and he just sort of lost sight of what the relationship was like as the tutor and as a student coming in for help with a paper. And he would come, like knock on one of the session room doors while I was tutoring someone else and ask for help, or he would have an appointment with another tutor and beg them to switch with me, or if I went outside to eat some lunch or have a conversation, he would follow me out with his laptop and just kind of follow me around the office.... And while they [writing center directors] were sympathetic, I was sort of expecting the system to be in place to kind of help me out, because I didn't want to hurt this guy's feelings or make him feel like tutoring wasn't okay or that I couldn't help him. I just needed the rules to be enforced. And since there was no one doing it, I kind of got stuck and he hasn't come back for a tutoring session since I had to say something about it.

At first I just kind of let him take advantage of the situation, because I just felt uncomfortable establishing rules. And it wasn't like he ever came to me to talk about anything that wasn't directly related to his papers. It is just that he thought, for some reason, that I was magically the only person who knew how to do MLA or who would read his memos quickly if he showed up late and you know offer advice. So I felt really uncomfortable and I didn't do much, and then eventually I was just like, I am sorry. I can't help you unless you make an appointment, and when you make an 
appointment you need to show up on time. If you miss your appointment, you need to call and cancel beforehand and you can't make appointments in other people's names or just show up and yeah, so eventually I suppose I handled it in the way that I was supposed to have.

New TAs struggle as they learn how to be authority figures, how to establish boundaries and rules with others in ways they have never had to before. As this participant explains - but hasn't had much opportunity to reflect on, yet - part of her challenge here was realizing that while she had mentors, there wasn't a "system" to save her from dealing with complicated human relationships. For perhaps the first time, she had to be the enforcer of policy, and moving into that role was deeply uncomfortable.

\section{Unsanctioned Teaching Narratives}

Three of the stories told in answer to this set of prompts elicited responses that we're pretty confident these instructors wouldn't have shared if we had been the ones doing the interviews - or at least not in the exact ways that they were reported here. One involved a behavior (a TA drinking a lot the night before a class so that she'd be sick and have a reason to cancel it) that is not a "sanctioned" response to a teaching challenge; in another account, a participant directly says "I don't know if I'm allowed to say this." While there are not many of these accounts, they hint at the kinds of complicated teaching experiences TAs face and point out the short supply of spaces for reflective conversation about such experiences: none of these stories made it to the mentor at the institution where the interview took place.

Two of these accounts, both by female instructors, involve intimidating male students. In one of these, the first-year instructor describes a student with whom she struggled all semester. An interviewer interpolates questions. The instructor says:

Okay. [This student] talks a lot. And he has some buddies in there, too. And they're a little bit more controllable, but this particular student is just completely, like - I guess not uncontrollable, but he just talks all the time, and just will make comments, and while I'm in the middle of doing something or talking to another student, and he'll just be completely - I don't know - out of - I don't know - I can't even . . . I just be like, "Please don't talk."

And the other day, he was way aggressive to me about a grade that I gave him. And I didn't think it was unfair, but he kind of was a little aggressive. And that was odd to me, because - I mean, he's a big guy, and he's a little scary. And he's been so obnoxious, really, in class, that I was just kind of - I think I handled it okay, but had 
to just remind myself not to get mad back at him, or react to his previous behavior.

But it was scary.

\section{How did you respond?}

Oh, yeah, I had to - I was like - I had to be calm, you know, "Hey, this is why I gave you the grade. I don't think it was unfair. These are the things you could have done better." But he was saying — he was just really, "I still don't understand ..." And I just had to remain calm, and that's hard. And especially with a student who I've been kind of mad at for the whole semester. So, that was tricky.

Why did you respond in this way?

Well, he, like - he was like, "Can you come talk to me?" And so I had to walk over there. It was after class; everyone else had gone, which was probably a little-

Unfortunately, she doesn't finish this thought, although the implication seems to be that it was not a wise choice to talk with this guy (who's "a little scary") alone in the classroom after class. This new instructor knew to "remain calm" even though she'd been "kind of mad" at him for the semester. Her story - about a student who made her mad all semester, a student she was scared of but met in private anyway, a student she did not tell the composition director about - reveals a new instructor trying to process what this experience meant for her and how she reacted. More generally, she tries to figure out whether this student is being appropriate in class or whether he might be "uncontrollable"; like other TAs, she might benefit from reflection and additional input into her analysis.

Another instructor, a second-year TA, relates a very different kind of ambiguous, challenging, ongoing experience that we have with students every once in a while - experiences for which senior faculty eventually develop a repertoire of responses. For her "tricky" situation, she describes a long and complicated account of working with a student who keeps insisting that she turned work in, and yet the instructor cannot find it. After this happens repeatedly throughout the semester, another mix-up occurs at the final portfolio time. The student hands in her portfolio to the instructor's mailboxwithout a required second essay. However, because of the ongoing complications, and because it's the end of the semester and the instructor is confused herself, she gives the portfolio a passing grade even though it's incomplete. She explains:

But that moment, I was just like - I was like - just wanted to be done with it. I read her portfolio; it didn't have the essay in it, but I just - I gave her like - I gave her a passing grade, trying to keep in mind that it was my fault that her paper was gone. 
It's probably like one of those moments that I'm not very proud of as a teacher, but I was really not - did not have a great semester, so I was just trying to get it done. But that was a really sticky situation, where I couldn't confront the student and say, "You're basically lying to me and I know it."

These unresolvable, uncomfortable scenarios are particularly tricky for new teachers, who haven't yet figured out what should be followed up on and what doesn't need to be. They're also the kind of scenario that is particularly useful for us as instructors: as mentors, we weren't aware of these situations, and so they give us glimpses into the decisions and reactions that new instructors make all the time whether we're available for feedback or not.

\section{TAs' Resources for Teaching Challenges}

These lively, honest, human accounts from new instructors reveal engaged, thoughtful people working to grow: to learn from their students, to be tentative, to think through teaching challenges and why they've approached them in the ways that they have. They are neither the stories of rank neophytes nor the stories of experienced faculty. These stories of pedagogy and of students again point to areas of inquiry for those of us who work to support new instructors; we might work, for example, to provide space for discussing "student" challenges - and then for reframing those challenges and revising responses to them.

Collectively, the participants utilized a range of strategies for how they responded to these challenging or tricky situations. Within their accounts, they note that they tried the following:

- Clarifying the issue, approach, or class with students directly (8)

- Taking another teaching approach (11)

- Taking another communication approach (e-mail, conferences, printed written instructions) (5)

- $\quad$ Sticking to a course policy (3)

- Reflecting on teaching practices/context (2)

- Remaining calm and using humor (2)

- Talking to a peer or mentor (1)

- Acknowledging students' frustration and reframing it as an opportunity for revision (1)

- Following up with resources beyond the classroom (counseling center) (1)

- Redoing final grades to give students benefit of the doubt (1)

- Being there for students when they struggle (1) 
Most of these strike us as healthy, productive reactions; it's wonderful that sixteen TAs identified ways in which they tried another approach after the initial teaching or communication approach wasn't successful, for example.

At the same time, we worry that simply "clarifying" an assignment, or "being there" for students, points toward a lack of resources: new instructors simply have not yet developed a large composition pedagogy repertoire. For example, a first-year TA first discusses his challenge of really getting students to write in an inquiry-based (rather than argumentative) way. His response, he says, is to "give the assignment and be there when they struggle." While he goes on to discuss this in a way that does echo program-wide goals, noting that he wants students to "experience cognitive dissonance," we wonder about the sparseness of approaches that he is able to recollect and apply.

Four TAs' accounts were unresolved or unsuccessful, but they acknowledged what they had learned for the next time they addressed a similar situation (developing models that they didn't yet have, for example, or intervening with a struggling student much earlier, or giving more guidance). For the majority of these TAs, the challenges were presented as resolved and they believed that they had learned from the incident. At the same time, the "unsanctioned" accounts and the accounts where TAs had few real resources for approaching these teaching challenges help us think about how to provide more effective and appropriate TA mentoring, across several semesters or even years, which we discuss below.

\section{Learning from TAs: Implications, Possibilities, Challenges}

As mentors of these TAs, we find that the implications of the two portions of interview data that we've focused on in this article loom large for us: what will we do now, knowing what we now know? Like so many of our colleagues, we teach in programs where the graduate curricular landscape is highly contested; we're experienced enough to know that institutional and cultural changes unfold slowly. Still, these data point us to reconsiderations for our own programs and for the teaching and mentoring of TAs in English departments, writing departments, and first-year writing programs across the country.

Just as scholars have worked hard within composition studies to make clear that first-year writing is not successful as a one-shot writing inoculation, so too do we need to make clear - in what we say, in our institutional structures, in our work with new TA instructors themselves - that one graduate pedagogy seminar is not and cannot be a one-shot teaching inoculation. Instead, we'll all benefit if we stop selling (or institutionally identifying) "the" TA pedagogy course as the one course to "get" it. Such a structure cre- 
ates several unintended repercussions. First, it tells our colleagues in other English subdisciplines that learning to teach is a relatively quick process to be moved through in a semester, and that graduate TAs are "done" after they've learned to teach first-year writing. This is the tale many of us were told, of course, and our own experiences years ago as TAs inevitably color discussions we initiate about supporting and mentoring TAs. However, the "we were given a textbook and did just fine" argument should not supplant data-based decisions, based on new knowledge about what it means to learn to teach.

Second, a one-semester approach - even a one-semester-plus approach, including lots of mentoring, meetings, informal workshops, and in-service/ in-services training - also tells these new graduate instructors that really they should be "done" after that initial experience (with perhaps some minor brushups here and there). As one TA in his third semester of teaching noted, he was "expecting to have ironed out some of these problems sooner." $\mathrm{He}$ continues, "I'm assuming that it's not just my inability to overcome problems [but] that it just seems that way . . . in a few ways, it's kind of frustrating just not being perfect." In contrast, we are reminded of Nancy Sommers and Laura Saltz's (2004) research on writing development over time: writing students are able to learn more, they note, when they are able to accept that they're novices and need to learn. When we communicate to new instructors early on that they can fully learn to teach in a short period of time, we shortcircuit their opportunities for growth. If, instead, it's clear to them that learning writing pedagogy really is a long-term process, then they can approach it as a different kind of puzzle to work with - a longer-term, ongoing, thousandpiece puzzle, not a quick teaching game.

Instead of settling for an approach that leaves TAs frustrated about imperfection after three semesters of teaching, we can aim to do better in what we preach and how we practice it. To counter the institutional message that people can learn writing pedagogy in a one-semester seminar, we imagine a variety of approaches appropriate for different institutions. Just as some first-year writing programs recognize the need to "stretch" writing instruction over two semesters and to advocate for an overt structure for writing pedagogy across an institution's curriculum, we too see the clear need to stretch our institutional approach to learning pedagogy. Two seminars is one possibility; another is an ongoing, required internship or colloquium for graduate credit that establishes a structure for regular meetings, discussions and reflection. At the same time, departments and programs can articulate their commitment to nurturing teacher-scholars through mission statements 
and program outcomes - for all programs of graduate study - that include an expectation of involvement with learning about teaching throughout each graduate student's program of study.

Moreover, the very interviews we conducted, as a genre, indicate to us how vital added spaces for guided discussions of teaching are. Teachers use talk to process, interpret, and analyze teaching experiences; interactions with other peer instructors (Nelson et al. 2010) and mentors (Rust 1999) are crucial to teacher development and growth (Cohen 2008; Miller 2008). Our set of interviews makes visible a continuum of talk about teaching, from mediated to less mediated, with the more-mediated discussions of the pedagogy seminar classroom on one end of the continuum and the informal interactions of the communal TA office at the other end. To foster third (and fourth) spaces for pedagogy talk, we imagine networks of sites for talk: mentoring groups, teaching circles, colloquia, discussion boards. We can make the ongoing process of learning to teach more visible through guided discussions where we might ask instructors - before, during, and especially after their pedagogy seminar - to identify the origins of their beliefs and then to re-see those possibilities in conversations with peers. On the principle that we should help new teachers practice what we want them to be able to do as reflective practitioners, we can ask them, at various points over several semesters, to identify teaching challenges and tricky situations from their classrooms and then help them reflect on and work to understand those challenges in light of multiple scholarly and communal resources. Such approaches will help TAs broaden their repertoire of possible approaches as well as sharpen their skills at creating reasonable responses to challenging pedagogical situations.

Our interview data does not let us directly evaluate the pedagogy classes we teach, the in-service training we provide, or the mentoring we encourage, but because we take responsibility for helping new instructors begin articulating and shaping their beliefs about teaching and their approaches to the classroom, what we learn from these interviews does help us think about our work in these settings. Do we play a key role in these new instructors' lives? Of course. Many voluntarily brought up ideas they had encountered in our pedagogy seminars, teaching approaches they had learned there, meetings they'd had with us as individuals. And yet, our work with them is one (important, we still think!) influence among multiple streams of influences, cultural models and expectations, and experiences that new instructors are negotiating. Their voices speak back to us, reminding us all to approach learning writing pedagogy as being as much of a developmental process as learning to write. 


\section{Appendix A: Research Site Characteristics}

Table 3. TA education and mentoring at the time of the study

\begin{tabular}{|c|c|c|}
\hline & George Mason University & Boise State University \\
\hline Yearly cohort & $\begin{array}{l}\text { Twelve to fourteen (mostly) } \\
\text { MFAs per cohort; up to half of } \\
\text { the } 3 \text { rd-year cohort moves from } \\
\text { TAships to nonteaching } \\
\text { fellowships }\end{array}$ & $\begin{array}{l}\text { Roughly seventeen MA TAships } \\
\text { (literature, rhetoric and composition) } \\
\text { and seventeen MFA TAships (poetry } \\
\text { or fiction) }\end{array}$ \\
\hline $\begin{array}{l}\text { Teaching } \\
\text { responsibilities }\end{array}$ & $\begin{array}{l}\text { 3-year TAship } \\
\text { Year 1: Writing Center tutoring } \\
\text { (complies with Southern Area } \\
\text { Colleges and Schools' 18-credit- } \\
\text { hour rule for teachers of record) } \\
\text { Year 2: Teach two FYG in fall, } \\
\text { two Intro to Literature classes } \\
\text { in spring } \\
\text { Year 3: Repeat Year } 2 \text { (option for } \\
\text { one Intro to Creative Writing } \\
\text { section) }\end{array}$ & $\begin{array}{l}\text { 3-year TAship } \\
\text { Year 1: Teach 1+2 1st-year composition } \\
\text { (FYC) each year } \\
\text { Year 2: Teach 1+2 FYC each year; a few } \\
\text { advanced opportunities for MA and } \\
\text { MFA students (literature surveys, } \\
\text { Writing Center, creative writing } \\
\text { 200-level courses) } \\
\text { Year 3: MFA students continue to teach } \\
\text { a combination of 200-level creative } \\
\text { writing courses and 1st-year writing } \\
\text { courses }\end{array}$ \\
\hline $\begin{array}{l}\text { FYC curricular } \\
\text { structure }\end{array}$ & $\begin{array}{l}\text { Learning-goals-based } \\
\text { curriculum; TAs choose texts } \\
\text { and create syllabi }\end{array}$ & $\begin{array}{l}\text { Outcomes-based curriculum; course } \\
\text { reader and syllabus initial outline } \\
\text { provided to } 3 \text { rd-year TAs; TAs choose } \\
\text { texts and create syllabi for subsequent } \\
\text { semesters }\end{array}$ \\
\hline $\begin{array}{l}\text { Preteaching } \\
\text { support }\end{array}$ & $\begin{array}{l}\text { Noncredit Writing Center } \\
\text { education; observations of } \\
\text { FYC sessions with mentor; } \\
\text { composition pedagogy seminar }\end{array}$ & $\begin{array}{l}\text { Online work during previous spring } \\
\text { and during summer; 8-day } \\
\text { presemester workshop in August }\end{array}$ \\
\hline $\begin{array}{l}\text { First-year pedagogy } \\
\text { education }\end{array}$ & $\begin{array}{l}\text { Monthly small group mentoring } \\
\text { and individual consultations; } \\
\text { two class observations; literature } \\
\text { pedagogy course in spring }\end{array}$ & $\begin{array}{l}\text { Graduate composition pedagogy } \\
\text { seminar in fall while teaching one } \\
\text { section of English 101; two class } \\
\text { observations of others; class } \\
\text { observation }\end{array}$ \\
\hline Continuing support & Informal mentoring in 3 rd year & $\begin{array}{l}\text { Informal professional development } \\
\text { meetings twice monthly in 2nd and } \\
\text { 3rd years; informal meetings and } \\
\text { classroom visits with mentor TA }\end{array}$ \\
\hline TAs as mentors & $\begin{array}{l}\text { May serve as mentor TAs in } \\
\text { 2nd or 3rd year }\end{array}$ & $\begin{array}{l}\text { May serve as mentor TAs in their 2nd } \\
\text { and 3rd years }\end{array}$ \\
\hline
\end{tabular}




\section{Appendix B: Interview Questions}

(Italicized questions are suggested for interviewer follow-up, if needed.)

1. What is your program status: first year, second year, third year?

2. Please state whether you are male or female.

3. How many complete semesters, including this one, have you tutored writing?

4. How many complete semesters, including this one, have you taught composition?

5. Did you teach or tutor somewhere else before you came to [university]? (What, and for how long?)

6. Which pedagogy classes have you taken so far - including any you are currently enrolled in?

7. Please tell me, what are some of your main steps or thought-processes as you prepare a writing-class syllabus? (Are there any other issues or goals you consider?)

8. Now can you tell me, what are some of your main steps or thought-processes as you prepare to teach/tutor a class meeting (or tutoring session)? (Are there any other issues or goals you consider?)

9. Please tell me a little about a tricky, difficult, or surprising situation you encountered recently related to teaching writing, either in class [while tutoring] or regarding a writing student [client]. (What was difficult or surprising about it?)

10. How did you respond? (How are you planning to respond?)

11. Why did (will) you respond that way?

12. What do you see as three or four key principles for your teaching [tutoring] of writing? (In other words, what do you think is important for you to do as a writing teacher [tutor]? What do you try always to do or not do?)

13. Could you say where those principles come from, or are related to? (Were they from something you read or learned, something you heard of or saw someone doing, some experience you had?) 
14. What one or two questions or issues remain most uncertain and/or challenging for you about teaching [tutoring] writing?

15. How do you cope with that uncertainty right now?

16. Do any (more) of your principles help you cope? [Interviewer may remind interviewee of answers to Question 12.]

17. Are there any other ways that the principles you mentioned earlier, or other principles, come into play as you plan classes or solve problems?

18. On a scale of 1 to 5 -with 1 being "not much at all" and 5 being "quite a lot" - how often do you find yourself thinking of your teaching-principles when you are involved in the following activities:

- $\quad$ planning your syllabus (even for those who are currently only tutoring)

- planning your class day or tutoring session

- teaching/tutoring your session

- $\quad$ responding to student writing

- problem solving as a teacher/tutor

19. Do you have other comments about or reflections on your recent teaching or teacher preparation that you'd like to add to this interview?

\section{Note}

Thanks to Jim Fredricksen for the phrase how people learn from pedagogy.

\section{Works Cited}

Barr Ebest, Sally. 2005. Changing the Way We Teach: Writing and Resistance in the Training of Teaching Assistants. Carbondale: Southern Illinois University Press.

Bishop, Wendy. 1990. Something Old, Something New: College Writing Teachers and Classroom Change. Carbondale: Southern Illinois University Press.

Briggs, Charles. 1986. Learning How to Ask: A Sociolinguistic Appraisal of the Role of the Interview in Social Science Research. Cambridge: Cambridge University Press.

Brooke, Robert. 1987. "Underlife and Writing Instruction." College Composition and Communication 38.2: 141-53.

Cohen, Jennifer L. 2008. " 'That's Not Treating You as a Professional': Teachers Constructing Complex Professional Identities through Talk." Teachers and Teaching: Theory and Practice 14.2: 79-93. 
Dobrin, Sidney I., ed. 2005. Don't Call It That: The Composition Practicum. Urbana, IL:

National Council of Teachers of English.

Estrem, Heidi, and E. Shelley Reid. 2012. "Writing Pedagogy Education: Instructor

Development in Composition Studies." In Exploring Composition Studies: Sites,

Issues, and Perspectives, ed. Kelly Ritter and Paul Matsuda, 223-40.Logan: Utah State

University Press.

Freire, Paulo. 1970. Pedagogy of the Oppressed. New York: Continuum.

Harris, Joseph. 1996. A Teaching Subject: Composition Since 1966. Logan: Utah State University Press.

Kennedy, Mary M. 1998. Learning to Teach Writing: Does Teacher Education Make a Difference? New York: Teachers College Press.

Miller, Matthew. 2008. "Problem-Based Conversations: Using Preservice Teachers'

Problems as a Mechanism for Their Professional Development." Teacher Education

Quarterly 35.4: 77-98.

Nelson, Tamara Holmlund, Angie Deuel, David Slavit, and Anne Kennedy. 2010. "Leading

Deep Conversations in Collaborative Inquiry Groups." Clearing House 83: 175-79.

Pytlik, Betty P., and Sarah Liggett. 2002. Preparing College Teachers of Writing: Histories,

Theories, Programs, Practices. New York: Oxford University Press.

Rankin, Elizabeth. 1994. Seeing Yourself as a Teacher: Conversations with Five New Teachers in a University Writing Program. Urbana, IL: National Council of Teachers of English.

Reid, E. Shelley, and Heidi Estrem. Forthcoming. "The Effects of Writing Pedagogy

Education on Graduate Teaching Assistants' Approaches to Teaching Composition."

WPA: Writing Program Administration.

Rust, Frances O'Connell. 1999. "Professional Conversations: New Teachers Explore

Teaching through Conversation, Story, and Narrative." Teaching and Teacher

Education 15: 367-80.

Seidman, Irving. 2006. Interviewing as Qualitative Research: A Guide for Researchers in Education and the Social Sciences. New York: Teachers College Press.

Soja, Edward. 1996. Thirdspace: Fourneys to Los Angeles and Other Real-and-Imagined Places. Cambridge, MA: Blackwell.

Sommers, Nancy, and Laura Saltz. 2004. "The Novice as Expert: Writing the Freshman Year." College Composition and Communication 56.1: 124-49.

Sprague, Jo, and Jody D. Nyquist. 1989. "TA Supervision." New Directions for Teaching and Learning 39: 37-53.

Ward, Irene, and Merry Perry. 2002. "A Selection of Strategies for Training Teaching

Assistants." In The Allyn \& Bacon Sourcebook for Writing Program Administrators, ed. Irene Ward and William J. Carpenter, 117-38. New York: Longman. 